\title{
Assessment of musculoskeletal system in women with jumping mechanography
}

This article was published in the following Dove Press journal:

International Journal of Women's Health

28 August 2009

Number of times this article has been viewed

\section{Yannis Dionyssiotis ${ }^{1,2}$ \\ Antonios Galanos' \\ Georgios Michas' \\ Georgios Trovas' \\ Georgios P Lyritis'}

'Laboratory for Research of the Musculoskeletal System, University of Athens, KAT Hospital, Kifissia, Greece; ${ }^{2}$ Rehabilitation Department, Rhodes General Hospital, Rhodes, Greece
Correspondence: Yannis Dionyssiotis Rehabilitation Department, Rhodes General Hospital, Agioi Apostoloi, 85100 , Rhodes, Dodekanese, Greece Tel +306946469759

Email idiony@otenet.gr
Abstract: The purpose of this study was to investigate and add reference data about the musculoskeletal system in women. The mechanography system of the Leonardo ${ }^{\mathrm{TM}}$ platform (Novotec, Germany) was used to measure parameters of movement (velocity, force, power) in 176 healthy Greek women aged 20-79 years, separated according to age decade in six groups: group $1(\mathrm{n}=12), 20-29$ years; group $2(\mathrm{n}=14), 30-39$ years; group $3(\mathrm{n}=33), 40-49$ years; group $4(\mathrm{n}=59), 50-59$ years including 21 postmenopausal; group $5(\mathrm{n}=31), 60-69$ years including 12 postmenopausal; and group $6(n=27), 70-79$ years all postmenopausal. This system measures forces applied to the plate over time, calculates through acceleration the vertical velocity of center of gravity and using force and velocity it calculates power of vertical movements. All women performed a counter-movement jump (brief squat before the jump) with freely moving arms. Weight was recorded on the platform before the jump and height was measured with a wall-mounted ruler. Body weight and body mass index were gradually increased; on the contrary height and all movement parameters except force (velocity, power) were statistically decreased during aging and after menopause.

Keywords: biomechanics, ground reaction force, power, women, menopause

\section{Introduction}

Nowadays, the lifestyle in western societies is changing. This change is followed by a dramatic increase in diseases related to impaired muscle function. ${ }^{1}$ In addition, it has been well documented that both muscle mass and power decline with age ${ }^{2-4}$ and this decline is associated with physical impairment and an increased risk of falls $\mathrm{s}^{5}$ and hip fractures ${ }^{6}$ leading to disability. In relation to movement disabilities, locomotion in the literature is described by confusing concepts that often do not agree with the rules and terms of physics. ${ }^{1}$ A scientific description of movement is needed in this area to enable researchers to communicate with one another. In the study of muscle performance, movement has to be described in terms of velocity and acceleration. Each movement is the action of force along a distance in a certain time and is therefore measured as power. ${ }^{7}$ This mechanical approach is in accordance with physics and enables the measurement and calculation of human movement using scientific concepts. ${ }^{8}$

For all these reasons, knowledge of parameters of the musculoskeletal system influencing muscle function in aging is important. The purpose of this paper is to compile reference data and discuss parameters of the locomotor (human musculoskeletal) system in Greek women. 


\section{Methods}

\section{Population}

The study population consisted of community dwelling women from different municipalities of Greece who visited the Laboratory for Research of the Musculoskeletal System in Athens for a screening program for osteoporosis. We included 176 healthy women aged 20-79 years without any musculoskeletal or neurologic disease. The women were separated according into six groups according to age: group $1(\mathrm{n}=12), 20-29$ years; group $2(\mathrm{n}=14), 30-39$ years; group $3(\mathrm{n}=33), 40-49$ years; group $4(\mathrm{n}=59)$, $50-59$ years including 21 postmenopausal; group $5(\mathrm{n}=31)$, 60-69 years including 12 postmenopausal; and group 6 $(n=27), 70-79$ years all postmenopausal. None of them were taking any antiosteoporotic drug or calcium/vitamin D supplements.

\section{Jumping mechanography system}

For the measurement of the objective parameters of movement we used the Leonardo ${ }^{\mathrm{TM}}$ Mechanography Ground Reaction Force Platform, (NOVOTEC Medical GmBH, Pforzheim, Germany). This system measures forces (f, Newton) applied to the plate over time. This means that stationary forces as well as the variation of forces over time (ground reaction forces) can be investigated. The vertical velocity is calculated through acceleration $(\mathrm{v}, \mathrm{m} / \mathrm{sec})$ of centre of gravity. Using force and velocity, the system calculates the power ( $p$, Watt) of vertical movements. The continuous registration of force, velocity, and power gives insight to the eccentric phases of movement. ${ }^{8}$ Jumping mechanography was recently found to be a reliable and sensitive measure of mobility performance in elite athletes as well as in frail patients. ${ }^{9}$

\section{Maximum height of two leg jump}

After explaining the process to the participants, all performed jumps (two-leg jump) on the Leonardo platform. The first phase of jumping was squatting as a counter-movement to store energy in the elastic elements. Jumping was performed with freely moving arms and the instruction was to jump with the head and chest as high as possible thus producing the maximum elevation of the center of mass. Each woman performed three counter-movement jumps. The jump of greatest height was used for data analysis. The most important outcome parameter of this test is the maximum power output (peak power) during the lift-off of the jump phase normalized to the body weight of the patient (personal power).

\section{Study parameters}

Weight $(\mathrm{kg})$ was recorded on the platform before the jump and height $(\mathrm{m})$ was measured with a wall-mounted ruler. Body mass index (BMI) was calculated for each subject $\left(\mathrm{BMI}=\right.$ weight $(\mathrm{kg}) /$ height $\left.^{2}\right)$. We studied kinematic and kinetic parameters (velocity, force, power, and power/weight as personal power). Subjects with velocity below $0.04 \mathrm{~m} / \mathrm{sec}$ in the examination were unable to follow the study methodology and were excluded.

\section{Statistical analysis}

All quantitative data were represented by the number of patients (n), mean value (mean), and standard deviation (SD), and qualitative data by the number of patients (n) and percentage (\%). Quantitative variables were analyzed using the one-way and two-way analysis of variance (ANOVA) models. Pairwise multiple comparisons took place using the Bonferroni test. Qualitative variables were analyzed using the $\chi^{2}$ test and Fisher's exact test. All tests are two-sided with 95\% significance level. Statistical analysis was performed using the statistical package SPSS (version 12.00; SPSS Inc., Chicago, IL, USA).

\section{Results}

Anthropometric and movement parameters of the study population are presented in Table 1. Height declined over the age range $(p<0.001)$, while body weight and BMI increased until the end of the sixth decade of life and thereafter decreased $(p=0.01$ and $p=0.001$, respectively). Multiple comparison analysis showed a significant difference in weight between group 2 versus groups 4,5 , and $6(p=0.047, p=0.05$, and $\mathrm{p}=0.046$, respectively), height between group 1 versus groups 4,5 , and $6(\mathrm{p}=0.027, \mathrm{p}=0.037$, and $\mathrm{p}=0.001$, respectively). BMI was significantly different between group 1 versus groups $4,5,6(\mathrm{p}=0.019, \mathrm{p}=0.022$, and $\mathrm{p}=0.001$, respectively) and between group 2 versus groups $4,5,6$ $(p=0.034, p=0.031, p=0.003$, respectively). Locomotor parameters in healthy women (except force, $p=0.085$ ), showed a progressive decrease $(\mathrm{p}<0.001)$ according to menopausal status and a negatively strong correlation with advancing age (velocity: $r=-0.58$, power: $r=-0.6$, power/weight: $r=-0.64$ ), which was greater for the parameters concerning power. Personal power declined continuously across the age range from the young to the elderly women (Figure 1).

\section{Discussion}

In this cross-sectional study, we measured musculoskeletal parameters to establish the changes with age in these variables. 
Table I Anthropometric data and movement parameters of Greek women in our population

\begin{tabular}{|c|c|c|c|c|c|c|c|}
\hline $\begin{array}{l}\text { Age } \\
\text { Data }\end{array}$ & $\begin{array}{l}20-29 \\
(n=12)\end{array}$ & $\begin{array}{l}30-39 \\
(n=14)\end{array}$ & $\begin{array}{l}40-49 \\
(n=33)\end{array}$ & $\begin{array}{l}50-59 \\
(n=59)\end{array}$ & $\begin{array}{l}60-69 \\
(n=31)\end{array}$ & $\begin{array}{l}70-79 \\
(n=27)\end{array}$ & p-value \\
\hline Weight (kg) & $58 \pm 9$ & $61 \pm 9$ & $63 \pm 10$ & $66 \pm 7$ & $68 \pm 12$ & $67 \pm 10$ & 0.011 \\
\hline Height (cm) & $165 \pm 0.07$ & $167 \pm 0.05$ & $164 \pm 0.06$ & $162 \pm 0.05$ & $161 \pm 0.05$ & $160 \pm 0.05$ & 0.0001 \\
\hline BMI $\left(\mathrm{kg} / \mathrm{m}^{2}\right)$ & $21.4 \pm 3.4 \mathrm{I}$ & $21.88 \pm 2.84$ & $23.56 \pm 3.47$ & $25 \pm 3.13$ & $26.13 \pm 4.62$ & $26 \pm 3.6$ & 0.0001 \\
\hline Velocity (m/sec) & $2.1 \pm 0.4 \mathrm{I}$ & $1.76 \pm 0.38$ & $1.69 \pm 0.39$ & $1.55 \pm 0.38$ & $1.32 \pm 0.23$ & $1.2 \pm 0.32$ & 0.001 \\
\hline Force $\max (\mathrm{KN})$ & $2.3 \pm 0.19$ & $2.18 \pm 0.22$ & $2 \pm 0.32$ & $1.94 \pm 0.27$ & $1.86 \pm 0.31$ & $1.71 \pm 0.20$ & 0.85 \\
\hline Power $(\mathrm{KW})$ & $2.1 \pm 0.5$ & $1.72 \pm 0.69$ & $1.68 \pm 0.42$ & $1.48 \pm 0.43$ & $1.25 \pm 0.33$ & $\mathrm{I} \pm 0.33$ & 0.0001 \\
\hline Power/weight (W/kg) & $37.2 \pm 8.8$ & $29.19 \pm 7.52$ & $27 \pm 8$ & $23.6 \pm 7$ & $18.84 \pm 4.8$ & $16.4 \pm 5.4$ & 0.0001 \\
\hline
\end{tabular}

Abbreviation: BMI, body mass index.

We also studied to what extent menopause had any influence on kinetic and kinematic parameters.

Changes in musculoskeletal system with age are becoming an important issue because of the increasingly elderly population. Reference values for kinetic and kinematic parameters might be useful in the clinical assessment of pathologies and the evaluation of therapeutic interventions. ${ }^{10-17}$

Fricke and Schoenau reviewed the literature and explained why anthropometric characteristics, mainly body height and body mass, are important factors which influence the recording of muscle function. ${ }^{18}$ Besides anthropometry, hormones also influence muscle function. Low postmenopausal estrogen levels were associated with lower strength of the abductor pollicis muscle. ${ }^{19}$

In our study population, body weight increased while height decreased with aging. In addition, younger generations tend to be taller meaning that the differences found

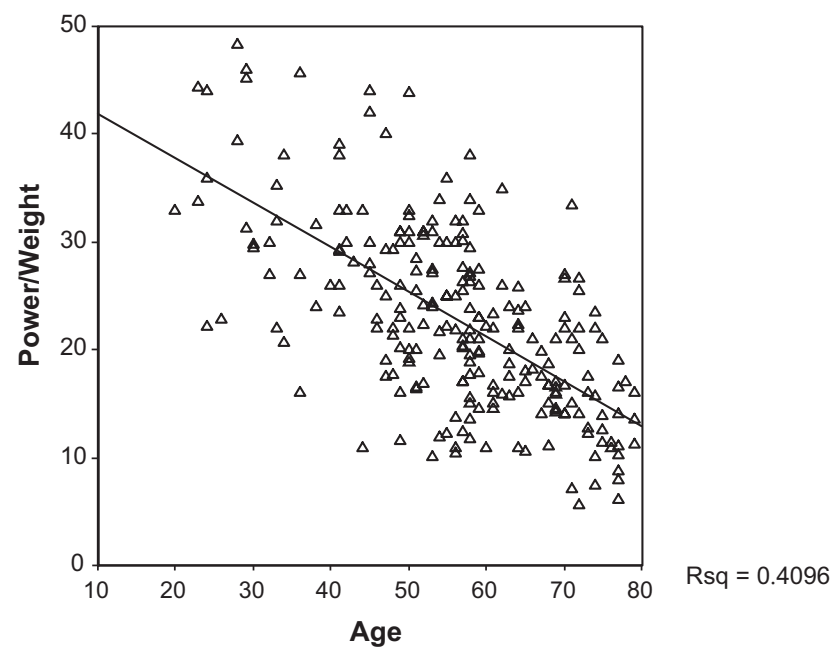

Figure I Age-declined power/weight parameter for Greek women $(y=45.98-0.41 x$, $\left.R^{2}=0.41 ; p<0.001\right)$. between young and old women could be partially associated with differences in height and weight. In women, weight is often gained because of less activity, higher calorie intake, or a loss in lean muscle. In most cases it is probably a combination of all three factors that makes women gain weight with age. In this study, women tended to start gaining weight during the perimenopausal period before the menopause. This is thought to be caused when estrogen levels are starting to decline. In our population, the BMI, a very simple measurement of fat, was slowly rising during aging until the end of the sixth decade of life. This was a consequence of the increase in body weight and decrease in height. However, and in line with this study, other authors noticed that BMI decreases in later years of life and the reason of this decrease above 80 years of age is sarcopenia, an age-related muscle mass loss. ${ }^{20-22}$ Aging is associated with anatomical changes leading to physical impairment because of a gradual loss of bone and a progressive decline in muscle mass and power. Weight stability in elderly years, also found in this study, is often a mark of sarcopenia, ${ }^{23}$ which is due in part to other age-related changes in body composition such as increased fat mass and BMI values $(\mathrm{p}<0.001$ versus groups $1-4) .^{24,25}$

Velocity declined during aging because the critical factor may be a greater percentage of slow twitch muscle fibers in older people which reduces the maximum contraction speed. ${ }^{26}$ In addition, the force we need for a movement against gravity is a summation of quickly released energy which has been previously stored in elastic elements during (eg, eccentric counter-movements), and currently generated muscle force by the actin-myosin-system. ${ }^{8}$ During old age, the elastic modulus of the Achilles tendon declines and whole tendon stiffness is decreased. ${ }^{27}$

There was a high statistical difference in force unrelated to age in every age decade of our sample. Sportive people 
have in this specific movement (two leg jumps at maximum height) a maximum force of $2.5 \pm 0.3$ times their body weight (Rawer Rainer, personal communication), which was not the case in our population of community dwelling women. Furthermore, we didn't find any significant difference in force among age decades, but found an accelerated post-menopausal fall-off in power $(\mathrm{p}=0.001)$ and strength $(\mathrm{p}=0.08, \mathrm{NS})$. According to Skelton and colleagues, muscle power is lost more rapidly than force between the ages of 65 and 90 years $(-3.5 \%$ per year for the former compared with about $1.8 \%$ for the latter) ${ }^{28}$ Cross-sectional studies have shown that elderly individuals are weaker than young adults ${ }^{29-31}$ and these reports are supported by longitudinal studies demonstrating a continual strength decline with aging, ${ }^{32-34}$ which is suggested to accelerate after the sixth decade of life. ${ }^{35}$ Nevertheless, force parameter losses appear to be partially reversible. ${ }^{36}$ For example, Morse and colleagues investigated the reversibility of the decline in specific force in old age in response to long-term (12 months) resistive loading of males aged over 70 years and found an increase $(p=0.05)$ in specific force. $^{37}$

Anthropometric characteristics, mainly body height and body mass, are important factors which influence the recording of muscle function. Therefore we need to evaluate power in relation to body size parameters. ${ }^{18}$ Dependent on personal power and weight, the comparison between persons according to weight results in the power/weight parameter. Runge and colleagues showed a very good correlation between maximum power output per body weight and age for both sexes separately in a healthy sportive reference collective. ${ }^{38}$ In Runge and colleagues' crosssectional study of more than 200 subjects aged between 18 and 88 years, the decline in power/weight parameter was more than $50 \%$ from the ages of 20 years to 80 years. ${ }^{38}$ In the women of our study, there was a $56 \%$ fall from the 20-29 decade versus the 70-79 decade and an accelerated postmenopausal fall-off in power. The decline in personal power was continuous across the entire age range from the young to the very elderly women. Possible reasons are changes in body composition, reduction of skeletal mass, and tendon properties. Several factors have to be considered for the age-related decline in power output and are well summarized in the paper by Runge and colleagues. ${ }^{38}$ According to these authors, fat mass and extracellular space increases with age and makes up a passive mass which does not contribute to strength or power, while muscle mass may be lost during aging to a different degree in different muscles. In sedentary and mildly active subjects, muscle thickness appears to decline $40 \%$ more with age in the vastus lateralis muscle than in the medial gastrocnemius muscle and this suggest that we need to consider locally specific patterns of muscle atrophy. A third group of explanatory mechanisms focuses on skeletal muscle. It has been recognized recently that, all things being equal, changes in muscle cross-sectional area (CSA) should affect output power more than proportionally. This effect could potentially explain why comparatively small reductions in muscle CSA with age in past studies were paralleled by a decline in power output. Moreover, and according to the same authors, aging appears to affect the muscle-fiber pennation angle.

Menopause has been linked to a reduction in lean mass (LM) and bone mineral density (BMD). ${ }^{39-41}$ It is easy to connect the loss of estrogens with the decline in muscle mass during aging. There is debate about the positive association of muscle mass and estrogens, but the strength of evidence in support of an anabolic effect of estrogens on skeletal muscle via meta-analysis outweighs the evidence of no effect. ${ }^{42-44}$

In conclusion, the study presents reference values measured by jumping mechanography in women. The data might be useful to assess pathologies and to study the effects of any therapeutic interventions according to muscles and power.

\section{Acknowledgments}

We would like to thank Johannes Willnecker and Rainer Rawer from Stratec, Pforzheim, Germany for technical advice and especially all the Greek women who took part in this study. The authors report no conflicts of interest.

\section{Disclosures}

Part of this paper was presented in the following congresses: 1) XXI Paulo Symposium on Preventing Bone Fragility and Fractures, Tampere, Finland, May 2006. Oral presentation: "Kinetic parameters in pre and postmenopausal women". 2) 6th Mediterranean Congress of Physical and Rehabilitation Medicine. Vilamoura, Portugal, October 18-21, 2006. Oral presentation. "Study of locomotive parameters in physically competent women". 3) 34th European Symposium on Calcified Tissues, May 2007, Copenhagen, Denmark. Poster presentation: "Physically competent women decline in kinetic parameters during aging". 4) 6th International Workshop for Musculoskeletal and Neuronal Interactions, Cologne 2008. Oral presentation: "Evaluation of 
muscle function in pre and postmenopausal women". 5) 16th European Congress of Physical and Rehabilitation Medicine, Bruges, June 2008, TESC competition. "Assessment of kinetic parameters in premenopausal and postmenopausal women with jumping mechanography".

\section{References}

1. Runge M. Measurement of human movements by mechanography. Abstracts book. Bad Liebenzell, Germany: International Society of Musculoskeletal and Neuronal Interactions, Black Forest Forum; May 2006.

2. Lindle RS, Metter EJ, Lynch NA, et al. Age and gender comparisons of muscle strength in 654 women and men aged 20-93 yrs. J Appl Physiol. 1997;83:1581-1587.

3. Kallman, DA, Plato CC, Tobin JD. The role of muscle loss in the age-related decline of grip strength: cross-sectional and longitudinal perspectives. J Gerontol A Biol Sci Med. 1990;45:M82-M88.

4. Larsson L, Grimby G, Karlsson J. Muscle strength and speed of movement in relation to age and muscle morphology. $J$ Appl Physiol. 1979;46:451-456.

5. Campbell AJ, Borrie MJ, Spears GF. Risk factors for falls in a community-based prospective study of people 70 years and older. J Gerontol. 1989;44:M112-M117.

6. Aniansson A, Zetterberg C, Hedberg M. Impaired muscle function with aging: a background factor in the incidence of fractures of the proximal end of the femur. Clin Orthop. 1984;191:192-210.

7. Runge M, Schieß1 H, Rittweger J. Klinische Diagnostik des Regelkreises Muskel-Knochen am Unterschenkel. Osteologie. 2002;1:25-37.

8. Runge M, Schacht E. Multifactorial pathogenesis of falls as a basis for multifactorial interventions. $J$ Musculoskelet Neuronal Interact. 2005;5:127-134.

9. Rittweger J, Schiessl H, Felsenberg D, Runge M. Reproducibility of the jumping mechanography as a test of mechanical power output in physically competent adult and elderly subjects. J Am Geriatr Soc. 2004;52:128-131.

10. Samson MM, Meeuwsen IB, Crowe A, Dessens JA, Duursma SA, Verhaar HJ. Relationships between physical performance measures, age, height and body weight in healthy adults. Age Ageing. 2000;29: 235-242.

11. Trueblood PR, Rubenstein LZ. Assessment of instability and gait in elderly persons. Compr Ther. 1991;17:20-29.

12. Imms FJ, Edholm OG. Studies of gait and mobility in the elderly. Age Ageing. 1981;10:147-156.

13. Andrews AW, Thomas M, Bohannon RW. Normative values for muscle strength obtained by hand-held dynamometry from individuals 50-79 years of age. Phys Ther. 1996;76:248-259.

14. Rothstein JM, Echternach JL, editors. Primer on Measurement: an introductory guide to measurement issues. Alexandria, VA: American Physical Therapy Association; 1993.

15. Rutherfold O, Welsh L. Effects of isometric strength training on quadriceps muscle properties in over 55 year olds. Eur J Appl Physiol. 1996;72:219-223.

16. Jette AM. A home based exercise program for nondisabled older adults. J Am Geriatr Soc. 1996;44:644-649.

17. Greig AJ, Young A, Skelton DA. Exercise studies with healthy volunteers. Age Ageing. 1994;23:185-189.

18. Fricke O, Schoenau E. Examining the developing skeletal muscle: Why, what and how? J Musculoskelet Neuronal Interact. 2005;5:225-231.

19. Philips SK, Bruce SA, Woledge RC, et al. Force and cross sectional area of adductor pollicis muscle in post menopausal women with and without hormone replacement therapy. J Phys. 1992;446:364-367.

20. Walsh MC, Hunter GR, Livingstone MB. Sarcopenia in premenopausal and postmenopausal women with osteopenia, osteoporosis and normal bone mineral density. Osteoporos Int. 2006;17:61-67.
21. Rosenberg IR, Roubenoff R. Stalking sarcopenia. Ann Intern Med. 1995;123:727-728.

22. Iannuzzi-Sucich M, Prestwood KM, Kenny AM. Prevalence of sarcopenia and predictors of skeletal muscle mass in healthy, older men and women. J Gerontol A Biol Sci Med Sci. 2002;57: M772-M777.

23. Gallagher D, Ruts E, Visser M, et al. Weight stability masks sarcopenia in elderly men and women. Am J Physiol Endocrinol Metab. 2000; 279:E366-E375.

24. Martini G, Valenti R, Giovani S, Nuti R. Age-related changes in body composition of healthy and osteoporotic women. Maturitas. 1997;27:25-33.

25. Hughes VA, Frontera WR, Roubenoff R, Evans WJ, Singh MA. Longitudinal changes in body composition in older men and women: role of body weight change and physical activity. Am J Clin Nutr. 2002;76:473-481.

26. Lexell J. Human aging, muscle mass, and fiber type composition. J Gerontol A Biol Sci Med Sci. 1995;50:11-16.

27. Narici MV, Maganaris CN, Reeves N. Muscle and tendon adaptations to ageing and spaceflight. J Gravit Physiol. 2002;9:137-138.

28. Skelton DA, Greig CA, Davies JM, Young A. Strength, power and related functional ability of healthy people aged $65-89$ years. Age Ageing. 1994;23:371-377.

29. Hortobagyi T, Zheng D, Weidner M, Lambert NJ, Westbrook S, Houmard JA. The influence of aging on muscle strength and muscle fiber characteristics with special reference to eccentric strength. J Gerontol A Biol Sci Med Sci. 1995;50:B399-B406.

30. Roos MR, Rice CL, Connelly DM, Vandervoort AA. Quadriceps muscle strength, contractile properties, and motor unit firing rates in young and old men. Muscle Nerve. 1999;22:1094-1103.

31. Macaluso A, Nimmo MA, Foster JE, Cockburn M, McMillan NC, De Vito G. Contractile muscle volume and agonist-antagonist coactivation account for differences in torque between young and older women. Muscle Nerve. 2002;25:858-863.

32. Winegard KJ, Hicks AL, Sale DG, Vandervoort AA. A 12-year follow-up study of ankle muscle function in older adults. $J$ Gerontol A Biol Sci Med Sci. 1996;51:B202-B207.

33. Lynch NA, Metter EJ, Lindle RS, et al. Muscle quality. I. Ageassociated differences between arm and leg muscle groups. $J$ Appl Physiol. 1999;86:188-194.

34. Frontera WR, Hughes VA, Fielding RA, Fiatarone MA, Evans WJ, Roubenoff R. Aging of skeletal muscle: a 12-yr longitudinal study. J Appl Physiol. 2000;88:1321-1326.

35. Narici MV, Bordini M, Cerretelli P. Effect of aging on human adductor pollicis muscle function. J Appl Physiol. 1991;71:1277-1281.

36. Reeves ND, Narici MV, Maganaris CN. Effect of resistance training on skeletal muscle-specific force in elderly humans. J Appl Physiol. 2004; $96: 885-892$.

37. Morse CI, Thom JM, Mian OS, Birch KM, Narici MV. Gastrocnemius specific force is increased in elderly males following a 12-month physical training programme. Eur J Appl Physiol. 2007;100: $563-570$.

38. Runge M, Rittweger J, Russo CR, Schiessl H, Felsenberg D. Is muscle power output a key factor in the age-related decline in physical performance? A comparison of muscle cross section, chair-rising test and jumping power. Clin Physiol Funct Imaging. 2004;24: 335-340.

39. Aloia JF, McGowan GM, Vaswani AN, Ross P, Cohn GD. Relationship of menopause to skeletal and muscle mass. Am J Clin Nutr. 1991;53: $1378-1383$.

40. Ley CJ, Lees B, Stevenson JC. Sex- and menopause associated changes in body fat distribution. Am J Clin Nutr. 1992;55:950-954.

41. Douchi T, Yamamoto S, Nackamura S. The effect of menopause on regional and body lean mass. Maturitas. 1998;29:247-252.

42. Ottenbacher KJ, Ottenbacher ME, Ottenbacher AJ, Acha AA, Ostir GV. Androgen treatment and muscle strength in elderly men: a meta-analysis. J Am Geriatr Soc. 2006;54:1666-1673. 
43. Hansen RD, Raja C, Baber RJ, Lieberman D, Allen BJ. Effects of 20-mg oestradiol implant therapy on bone mineral density, fat distribution and muscle mass in postmenopausal women. Acta Diabetol. 2003;40:S191-S195.
44. Brown M. Skeletal muscle and bone: effect of sex steroids and aging. Adv Physiol Educ. 2008;32:120-126.

International Journal of Women's Health

Dovepress

\section{Publish your work in this journal}

The International Journal of Women's Health is an international, peerreviewed open-access journal publishing original research, reports, reviews and commentaries on all aspects of women's healthcare including gynaecology, obstetrics, and breast cancer. Subject areas include: Chronic conditions (migraine headaches, arthritis, osteoporosis);

Endocrine and autoimmune syndromes; Sexual and reproductive health; Psychological and psychosocial conditions. The manuscript management system is completely online and includes a very quick and fair peer-review system. Visit http://www.dovepress.com/ testimonials.php to read real quotes from published authors. 